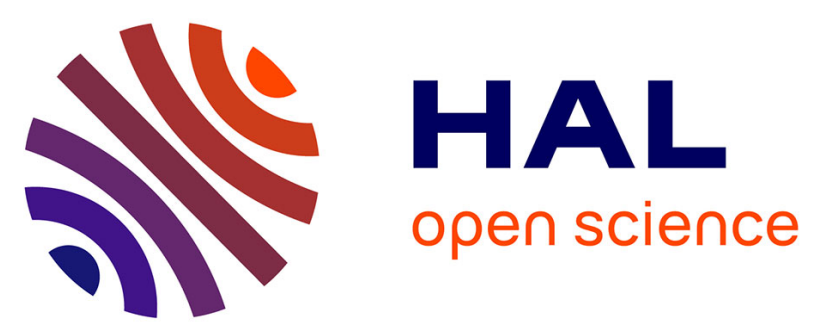

\title{
Mode of delivery and mortality and morbidity for very preterm singleton infants in a breech position: A European cohort study
}

Stephan Schmidt, Mikael Norman, Bjorn Misselwitz, Aurélie Piedvache, Lene D. Huusom, Heili Varendi, Henrique Barros, Hendrik Cammu, Béatrice Blondel, Joachim Dudenhausen, et al.

\section{To cite this version:}

Stephan Schmidt, Mikael Norman, Bjorn Misselwitz, Aurélie Piedvache, Lene D. Huusom, et al.. Mode of delivery and mortality and morbidity for very preterm singleton infants in a breech position: A European cohort study. European Journal of Obstetrics \& Gynecology and Reproductive Biology, 2019, 234, pp.96 - 102. 10.1016/j.ejogrb.2019.01.003 . hal-03486891

\section{HAL Id: hal-03486891 https://hal.science/hal-03486891}

Submitted on 20 Dec 2021

HAL is a multi-disciplinary open access archive for the deposit and dissemination of scientific research documents, whether they are published or not. The documents may come from teaching and research institutions in France or abroad, or from public or private research centers.
L'archive ouverte pluridisciplinaire HAL, est destinée au dépôt et à la diffusion de documents scientifiques de niveau recherche, publiés ou non, émanant des établissements d'enseignement et de recherche français ou étrangers, des laboratoires publics ou privés.

\section{(ㄷ)(1) $\$$}

Distributed under a Creative Commons Attribution - NonCommerciall 4.0 International 
Version of Record: https://www.sciencedirect.com/science/article/pii/S0301211519300247

Manuscript_e0c01ae06fa4784d845662d952dc4a68

\section{Mode of delivery and mortality and morbidity for very preterm singleton infants in a}

\section{breech position: a European cohort study}

Stephan Schmidt ${ }^{1}$, Mikael Norman ${ }^{2,3}$, Bjorn Misselwitz ${ }^{4}$, Aurélie Piedvache, ${ }^{4}$ Lene D. Huusom $^{6}$, Heili Varendi ${ }^{7}$, Henrique Barros ${ }^{8}$, Hendrik Cammu ${ }^{9}$ Béatrice Blondel ${ }^{5}$, Joachim Dudenhausen ${ }^{10}$, Jennifer Zeitlin ${ }^{5}$, Tom Weber ${ }^{6}$ for the EPICE Research Group ${ }^{11}$

\section{Affiliations}

1. Department of Obstetrics, University Hospital, Philipps University, Marburg, D-35043, Germany

2. Department of Clinical Science, Intervention \& Technology, Karolinska Institutet, Stockholm, Sweden

3. Department of Neonatal Medicine, Karolinska University Hospital, Stockholm, Sweden

4. Institute of Quality Assurance Hesse, Eschborn, Germany

5. Inserm UMR 1153, Obstetrical, Perinatal and Pediatric Epidemiology Research Team (Epopé), Center for Epidemiology and Statistics Sorbonne Paris Cité, DHU Risks in pregnancy, Paris Descartes University, Paris, France

6. Department of Obstetrics, Hvidovre University Hospital, Hvidovre, Denmark

7. University of Tartu, Tartu University Hospital, Tartu, Estonia

8. EPIUnit-Institute of Public Health, University of Porto, Porto, Portugal

9. H Cammu, Study centre of Perinatal Epidemiology \& Vrije Universiteit Brussel, Belgium

10. Department of Obstetrics, Charité - University Medicine Berlin, Germany

11. EPICE (Effective Perinatal Intensive Care in Europe) Research Group; collaborators:

BELGIUM: Flanders (E Martens, G Martens, P Van Reempts); DENMARK: Eastern Region (K Boerch, A Hasselager, LD Huusom, O Pryds, T Weber); ESTONIA (L Toome, H Varendi); FRANCE: Burgundy, Ile-de France and Northern Region (PY Ancel, B Blondel, A Burguet, PH Jarreau, P Truffert); GERMANY: Hesse (RF Maier, B Misselwitz, S Schmidt), Saarland (L Gortner); ITALY: Emilia Romagna (D Baronciani, G Gargano), Lazio (R Agostino, D DiLallo, F Franco), Marche (V Carnielli), M Cuttini; ; NETHERLANDS: Eastern \& Central (C KoopmanEsseboom, A van Heijst, J Nijman); POLAND: Wielkopolska (J Gadzinowski, J Mazela); PORTUGAL: Lisbon and Tagus Valley (LM Graça, MC Machado), Northern region (Carina Rodrigues, T Rodrigues), H Barros; SWEDEN: Stockholm (AK Bonamy, M Norman, E Wilson); UK: East Midlands and Yorkshire and Humber (E Boyle, ES Draper, BN Manktelow), Northern Region (AC Fenton, DWA Milligan); INSERM, Paris (J Zeitlin, M Bonet, A Piedvache). Inserm UMR 1153, Obstetrical, Perinatal and Pediatric Epidemiology Research Team (Epopé), Center for Epidemiology and Statistics Sorbonne Paris Cité, DHU Risks in pregnancy, Paris Descartes University, France 


\section{Corresponding Author}

Jennifer Zeitlin

Obstetrical, Perinatal and Pediatric Epidemiology Research Team

INSERM U1153

53 avenue de l'Observatoire

Paris 75014

Jennifer.zeitlin@inserm.fr 


\section{Abstract}

Objective: Caesarean section (CS) may reduce mortality and morbidity for very preterm breech infants, but evidence is inconclusive. We evaluated neonatal outcomes for singleton breech infants by mode of delivery in a European cohort.

Study Design: Data come from the EPICE population-based cohort of very preterm births in 19 regions in 11 European countries ( 7770 live births). The study population was singleton spontaneous-onset breech births at 24-31 weeks gestational age (GA) without antenatal medical complications requiring caesarean delivery ( $N=572)$. Mixed-effects regression models adjusting for maternal and pregnancy covariates and propensity score matching was used to examine the effect of (1) CS and (2) a unit policy of systematic CS for breech presentation by GA. The primary outcome was a composite of in-hospital mortality, intraventricular haemorrhage grades III \& IV or cystic periventricular leukomalacia.

Secondary outcomes were each component separately, five minute Apgar score below seven and mortality within six hours of delivery.

Results: $64.4 \%$ of infants were delivered by CS with a range across regions from $41 \%$ to $100 \%$; these infants had higher GA and were more likely to be small for gestational age, receive antenatal steroids, and have mothers who were hospitalised for more than one day before delivery compared to those delivered vaginally. CS was associated with lower risks of all outcomes in mixed-effects adjusted models (odds ratio (OR) for the composite outcome: $0.50,95 \%$ confidence interval $(\mathrm{Cl}): 0.30-0.81$ ), but not in propensity score matched models (OR: $0.72,95 \% \mathrm{Cl}: 0.41 ; 1.29$ ). A systematic CS policy was associated with lower mortality and morbidity in unadjusted, but not adjusted models (OR for composite outcome: 0.76, $95 \% \mathrm{Cl}: 0.44 ; 1.28) .35 \%$ of births $24-25$ weeks were delivered by CS and protective effects were consistently stronger, but not statistically significant.

Conclusions: Point estimates indicated protective effects of caesarean delivery for very preterm breech infants in conventional statistical models. However, analyses using propensity scores and based on unit policies did not confirm statistically significant associations. Prospective large-scale studies are needed to establish best practice and could be implemented in European regions where vaginal delivery remains an option.

\section{5 words}




\section{Funding}

The EPICE project was funded from the European Union's Seventh Framework Programme (FP7/2007-2013) under grant agreement $n^{\circ} 259882$. Additional funding was received for the EPICE project in the following regions: France (French Institute of Public Health

Research/Institute of Public Health and its partners the French Health Ministry, the National Institute of Health and Medical Research, the National Institute of Cancer, and the National Solidarity Fund for Autonomy; grant ANR-11-EQPX-0038 from the National Research Agency through the French Equipex Program of Investments in the Future; and the PremUp Foundation); Poland (2012-2015 allocation of funds for international projects from the Polish Ministry of Science and Higher Education); Portugal (by FEDER through the Operational Programme Competitiveness and Internationalization and national funding from the Foundation for Science and Technology - FCT (Portuguese Ministry of Science, Technology and Higher Education), under the Unidade de Investigação em Epidemiologia - Instituto de Saúde Pública da Universidade do Porto); UK (funding for The Neonatal Survey from Neonatal Networks for East Midlands and Yorkshire \& Humber regions).

Keywords: caesarean delivery, mode of delivery, breech position, very preterm birth, propensity score matching, maternity unit policies

\section{Manuscript word count: 2473}




\section{Introduction}

About $20 \%$ of all very preterm infants present in a breech position. ${ }^{1}$ In recommending mode of delivery for very preterm breech, clinicians have to balance the risks to the mother of caesarean section (CS) in early gestation with the potential benefits for the infant. Maternal risks include bleeding and infection and complications of placenta praevia or accreta and uterine rupture in subsequent pregnancies. ${ }^{23}$ While CS may be the only option for certain maternal or fetal conditions, such as imminent eclampsia, placenta praevia or fetal distress, ${ }^{4}$ a choice of mode of delivery is possible during uncomplicated labour. In such cases, the risks and benefits for the infant in relation to mode of delivery are still unclear.

Attempts to carry out randomized trials have failed because of the difficulties of recruiting women in labour and achieving equipoise among clinicians. ${ }^{56} \mathrm{~A}$ Cochrane review concluded that the evidence was not sufficient to provide a recommendation for breech very preterm births. ${ }^{2}$ Best available knowledge therefore comes from observational studies, challenged by confounding by indication. Preterm breech infants delivered vaginally are more often born at lower gestations, with advanced progression of labour and without antenatal steroids; on the other hand, CS can reflect poor progression during labour and fetal distress. Using the intended, as opposed to actual, mode of delivery minimizes indication bias, but is difficult to define. $^{7}$

Reviews of observational studies have found that CS for breech very preterm births before 32 weeks of $\mathrm{GA}^{8}$ and extremely preterm before 28 weeks ${ }^{9}$ seems to confer an overall benefit for neonatal mortality and morbidity and these findings are supported by many, ${ }^{10-12}$ but not all ${ }^{13}$ recent studies. Studies showing protective effects have been questioned on 
methodological grounds ${ }^{7}$ and methodological limitations have been acknowledged in systematic reviews. ${ }^{8}$ Several studies focusing on unit policies, which are less susceptible to indication bias, have not documented an impact of CS policies on morbidity and mortality. ${ }^{14}$

Given this continuing debate, we explored the association between CS and neonatal outcome among breech very preterm births using data from a large, population-based cohort in Europe with information on mode of delivery and maternity unit policies.

\section{Methods}

Data source

Data are from the EPICE (Effective Perinatal Intensive Care in Europe) study, a geographically defined cohort study of all very preterm births from $22+0$ to $31+6$ weeks GA in 19 regions in 11 European countries (listed in Table 1). The study's overall aim was to investigate the use of evidence-based care for very preterm births. ${ }^{16}$ Data were collected over a 12 month period starting between March and July 2011, except in France (6 months only).

Investigators abstracted data from obstetrical and neonatal charts using a pretested standardised questionnaire with common definitions. Infants were followed up until discharge from hospital. Data on the characteristics, policies and protocols of maternal and neonatal units were collected using structured pretested questionnaires sent to heads of services with at least 10 very preterm admissions per year.

Ethics approval was obtained in each study region from regional and/or hospital ethics committees, as required by national legislation. The European study was also approved by 
the French Advisory Committee on Use of Health Data in Medical Research and the French National Commission for Data Protection and Liberties.

\section{Study population}

We included live born infants in a breech position with spontaneous onset of labour or preterm premature rupture of membranes (PPROM) from $24+0$ to $31+6$ weeks GA. We excluded births before 24 weeks of GA because of variation in practices of active management across regions ( $\mathrm{N}=99$ births). ${ }^{17}$ Other exclusions were severe congenital anomalies ( $n=30)$, multiple pregnancies $(n=745)$, out-of-hospital deliveries $(n=1)$, missing mode of delivery $(n=7)$ and situations in which CS is indicated or strongly recommended, including preeclampsia, eclampsia and HELLP $(n=18)$ a diagnosis of severe fetal growth restriction $(\mathrm{N}=32), \mathrm{CS}$ for maternal conditions $(\mathrm{N}=56)$ and other conditions for which $\mathrm{CS}$ is indicated ( $N=71$, see Table S1). Our aim was to identify infants for whom a vaginal delivery could be considered. The final sample included 572 infants, as described in Figure 1.

\section{Exposure variables}

Our principal exposure variable was mode of delivery. In secondary analyses, the exposure was delivery in a hospital with a policy of systematic use of CS for breech deliveries, based on responses to the question: "In case of breech presentation associated with preterm labour in a singleton pregnancy without other complications, what is the recommended mode of delivery in the unit before 32 weeks GA?" For each GA in completed weeks, possible responses were vaginal, CS or no recommendation/depends on attending physician. Each birth at a given GA was classified by whether the delivery hospital had a systematic policy of CS at that GA. In our sample, $37(6.5 \%)$ were born in a hospital that did not have a 
unit questionnaire, either because it was a small unit to which questionnaires were not sent or because the unit did not reply (12 eligible units). Therefore this exposure was assessed on 535 infants.

\section{Outcome variables}

Our principal outcome measure was a composite measure including in-hospital mortality, including labour ward deaths and deaths in the neonatal units until discharge from hospital, or severe intraventricular haemorrhage (IVH), according to Papile Grades III-IV ${ }^{18}$ or cystic periventricular leukomalacia (cPVL). Secondary outcomes were each component separately as well as immediate death, defined as death in the first 6 hours of life, and a five minute Apgar score less than seven. Infants without a cranial ultrasound (US) had missing data for IVH and CPVL and were excluded from models using this outcome. Cranial US were more often missing for infants who died soon after delivery.

\section{Co-variables}

We selected co-variables hypothesized to affect the probability of CS as well as the outcome variables based on the scientific literature, biological plausibility and previous analyses of our

cohort. ${ }^{1920}$ Variables included advanced maternal age (35 years or over), parity and whether the mother had a previous CS (classified as primiparous, multiparous without previous CS and multiparous with previous CS), PPROM, the presence of infections, if noted as an indication for delivery or if chorioamnionitis was mentioned in the medical records, antepartum haemorrhage after 20 weeks GA and admission to hospital for preterm labour after 20 weeks GA, receipt of antenatal steroids (any), whether the delivery occurred the same day as admission to hospital, and the maternity unit's level of care using local 
designations. Neonatal characteristics were GA in completed weeks, infant sex, small for gestational age (SGA) defined using intrauterine references developed for the EPICE cohort ${ }^{21}$ and classified as $<3^{\text {rd }}$ percentile, 3 to $<$ the $10^{\text {th }}$ percentile and $\geq 10^{\text {th }}$ percentile).

\section{Analysis strategy}

We first described the characteristics of our sample overall and by mode of delivery and the unit policies regarding systematic CS. Then we modelled the crude association of CS with mortality and morbidity and adjusted for co-variables using multilevel logistic regressions with region and unit random effects. To better take into consideration indication bias, we

ran propensity score matched models. ${ }^{22}$ Propensity score matching estimates the probability of being born by CS given the available co-variables in the dataset and matches pairs of infants with and without CS that share a similar probability of having a CS. Infants that cannot be matched are excluded from the analyses (i.e. vaginal deliveries with a very low probability of CS and caesarean deliveries with a very high probability of CS). This method is widely used to address indication bias in observational studies. ${ }^{23}$ Because CS rates were much lower for infants below $26+0$ weeks of GA, we reran all models for this sub-group separately. A final set of models compared the outcomes of breech infants by maternity unit policies of systematic CS.

\section{Results}

\section{Characteristics of the sample}

Our sample included 572 very preterm infants delivered in a breech position. One-quarter had a mother 35 years or older and half had a nulliparous mother (Table 1); PPROM occurred in $44.8 \%$ of cases. Over $85 \%$ received antenatal steroids and $79.5 \%$ delivered in a 
level III unit; most women had been hospitalized at least one day before the delivery. Twenty-four percent of infants were born at 24 or 25 weeks of GA.

\section{Clinical factors related to caesarean delivery}

The CS rate was $64.4 \%$. CS were more common among infants with a nulliparous mother or a multiparous mother with a previous CS. Other associated factors were administration of antenatal steroids and hospitalization for more than one day. Thirty-five percent of deliveries at $24-25$ weeks were by CS versus $77.7 \%$ at $30-31$ weeks. CS were carried out in over $90 \%$ of breech deliveries in Denmark, Estonia, Germany and Sweden versus less than $50 \%$ in the Netherlands, France and the UK.

\section{Unit policies}

Unit policies reflected regional differences, but also revealed heterogeneity within regions (Table 2). A policy of systematic CS was associated with observed rates: $89.6 \%$ versus $42.5 \%$ when there was no such policy (Supplementary Figure 1).

Comparing outcomes by mode of delivery

In unadjusted and adjusted multivariable mixed effects models, CS was associated with lower odds of mortality or IVH 3-4 or CPVL, mortality, mortality in the first 6 hours, Apgar scores $<7$ and IVH 3-4 or cPVL (Table 3). After propensity score matching, the associations were attenuated and no longer statistically significant. Propensity matched analyses included a smaller number of infants (214/572) because of the different risk profiles of caesarean versus vaginal deliveries, as shown by the distribution of the propensity scores (Figure S2). Births included in the propensity matched sample were less likely to be at the 
extremes of gestation, with very high or low birthweights and to have a combination of the characteristics that were either strongly negatively or positively associated with caesarean deliver shown in Table 1. Odds of adverse outcomes associated with CS were lower at 24-25 weeks than for later gestations, but were not significant. The negative association of CS with immediate mortality was marked; few infants died in the 6 hours following a CS.

Comparing outcomes by unit policy

Units with systematic CS policies for breech deliveries had lower unadjusted mortality and morbidity, but these effects were insignificant after adjustment. The overall composite OR associated with systematic CS policies of 0.72 (95\% confidence interval: 0.41 to 1.29 ), was similar to individual level results after propensity score matching of 0.76 ( $95 \% \mathrm{Cl}: 0.44$ to 1.28).

\section{Discussion}

\section{Main findings}

Sixty-four percent of our sample of 572 singleton very preterm breech infants were delivered by CS with variability across European regions from $41 \%$ to $100 \%$. These infants differed from those delivered vaginally, as shown by a low number of infants eligible for matched propensity score analyses. CS was protective for all mortality and morbidity outcomes in unadjusted and adjusted mixed effects regression models, but not after propensity score matching. Maternity unit policies of systematic CS varied widely and confirmed the absence of a consensus on mode of delivery for breech deliveries across regions and units of Europe. After adjustment, having a unit policy of systematic CS was not related to lower mortality and morbidity. 


\section{Strengths and Limitations}

The study's strengths were a large overall sample of infants, use of a pre-tested protocol for medical record abstraction and heterogeneity in practices across units. Data were available on maternal and pregnancy complications to define a population eligible for vaginal delivery, and maternal and neonatal characteristics were used to compute propensity scores to match for risk profiles. We also had data on unit policies, which are less susceptible to indication bias. Limitations include lack of information on the intention of the medical team before delivery and on the reasons for carrying out a CS. As these births occurred in $2011 / 2012$, it is also possible that caesarean rates have changed, although the debate about the effectiveness of caesarean breech infants has continued over this period. ${ }^{13}$ Finally, the time frame of our study was short and it does not provide longer term health assessments, such as neurodevelopmental outcomes. ${ }^{24}$

\section{Interpretation}

As found previously, our data show that vaginal and caesarean breech very preterm births are different. ${ }^{111}$ Infants born vaginally had lower GA, did not receive antenatal steroids and were more often born the same day as admission, suggesting some cases resulted from precipitous delivery or were linked to decisions to abstain from active management. This latter interpretation is consistent with the higher proportion of deaths occurring before 6 hours of life among vaginal births. Alternatively, it could suggest a strong negative impact of vaginal delivery in these fragile infants.

The odds ratio from adjusted mixed effects models showing lower mortality associated with CS of $0.51(95 \% \mathrm{Cl}: 0.29 ; 0.88)$ was similar to pooled odds ratios from recent meta-analyses: 
$0.59(95 \% \mathrm{Cl} 0.36-0.95)$ in the reviews by Grabovac et $\mathrm{al}^{9}$ and $0.63(95 \% \mathrm{Cl} 0.48-0.81)$ by Bergenhenegouwen et al. ${ }^{8}$ Other recent studies also found lower mortality for CS among breech extremely preterm infants, ${ }^{11}{ }^{12}$ including a Canadian neonatal network study which reported a similar result for mortality $(0.56$ (95\% Cl: $0.43-0.77)$, but not for severe IVH or PVL $\left(0.91\right.$ (95\% Cl: 0.67-1.11). ${ }^{25}$

When we used propensity score matched models, odds ratios were attenuated and not significant. Because the vaginal and CS groups were so different, the matched sample was smaller than the overall sample (214 versus 572 ), illustrating the challenges facing researchers comparing practices in observational studies. A recent study from the French EPIPAGE2 cohort used propensity score matching and also reported no association between CS and mortality and neonatal morbidity, as well as neurodevelopment at 2 years of age. ${ }^{13}$ The strong impact of model choice on our results calls for caution in interpreting results from studies without adequate case-mix adjustment. None of the studies in the previously cited reviews ${ }^{89}$ used propensity score methods, recommended for addressing confounding by indication. ${ }^{22}$ Results from our models based on unit policies, which are less likely to suffer from bias, were consistent with the propensity matched models, yielding non-significant odds ratio of 0.7 .

The CS rate was lowest in the most preterm breech deliveries at 24 and 25 weeks GA. In this group of very immature infants, severe brain damage is of particular concern. Although our final estimates were not significant, our finding of the lowest odds for severe brain injury among the most immature babies raises the possibility that CS for breech may be particularly effective in these patients. Since cranial ultrasound was only performed in infants undergoing neonatal intensive care, our findings in this patient group may be less 
susceptible to indication bias. Vaginally born breech extremely preterm infants were at high risk for later neurodevelopmental delay in the EXPRESS Study. ${ }^{24}$ The stakes are therefore high for better evidence about the causality of this relationship.

In conclusion, although point estimates indicated protective effects of CS, these effects were not significant after applying propensity score matching and using unit policy variables which are less susceptible to indication bias. Our results illustrate the need to consider bias carefully in observational research and suggest that most commonly used multivariable modelling may over-estimate the protective effects of CS. Given the possibility that CS may improve outcomes for very preterm infants in a breech position and, in particular, for the most preterm infants at highest risk, sufficiently powered high quality prospective studies with techniques to mitigate indication bias are needed to determine causality and could be conducted in European regions where vaginal delivery of breech very preterm infants remains an option.

\section{Acknowledgements}

We would like to acknowledge the participation of the Departments of Obstetrics and Neonatology from the hospitals in the EPICE regions.

\section{Disclosure of Interests}

The authors have no conflicts of interest to disclose

\section{Contribution to Authorship}


Author Contributions: JZ had full access to all of the data in the study and take responsibility for the integrity of the data and the accuracy of the data analysis; Study concept and design: SS, MN, JZ, TW; Acquisition, analysis, or interpretation of data: SS, MN, JZ, TW, AP, BM, LDH, $\mathrm{HV}, \mathrm{HB}, \mathrm{HC}, \mathrm{BB}, \mathrm{JD}$ and all authors in Epice Research Group; Drafting of the manuscript: SS, MN, JZ, TW Critical revision of the manuscript for important intellectual content and approval of final version of the manuscript: All authors; Statistical analysis: AP, BM

\section{Details of ethics approval}

Ethics approval was obtained in each study region from regional and/or hospital ethics committees, as required by national legislation. The European study was also approved by the French Advisory Committee on Use of Health Data in Medical Research ( $N^{\circ} 13.020$ on 24/01/2013) and the French National Commission for Data Protection and Liberties (DR2013-194, on $10 / 04 / 2013)$.

\section{Funding}

The EPICE project was funded from the European Union's Seventh Framework Programme (FP7/2007-2013) under grant agreement $n^{\circ} 259882$. Additional funding was received for the EPICE project in the following regions: France (French Institute of Public Health Research/Institute of Public Health and its partners the French Health Ministry, the National Institute of Health and Medical Research, the National Institute of Cancer, and the National Solidarity Fund for Autonomy; grant ANR-11-EQPX-0038 from the National Research Agency through the French Equipex Program of Investments in the Future; and the PremUp Foundation); Poland (2012-2015 allocation of funds for international projects from the Polish Ministry of Science and Higher Education); Portugal (by FEDER through the Operational Programme Competitiveness and Internationalization and national funding from the 
Foundation for Science and Technology - FCT (Portuguese Ministry of Science, Technology and Higher Education), under the Unidade de Investigação em Epidemiologia - Instituto de Saúde Pública da Universidade do Porto); UK (funding for The Neonatal Survey from Neonatal Networks for East Midlands and Yorkshire \& Humber regions). 


\section{References}

1. Lorthe $E$, Quere $M$, Sentilhes $L$, et al. Incidence and risk factors of caesarean section in preterm breech births: A population-based cohort study. Eur J Obstet Gynecol Reprod Biol 2017;212:37-43. doi: 10.1016/j.ejogrb.2017.03.019

2. Alfirevic Z, Milan SJ, Livio S. Caesarean section versus vaginal delivery for preterm birth in singletons. Cochrane Database Syst Rev 2013(9):CD000078. doi: 10.1002/14651858.CD000078.pub3

3. Lee HC, Gould J. Survival advantage associated with cesarean delivery in very low birth weight vertex neonates. Obstet Gynecol 2007;109(5):1203. doi: 10.1097/01.AOG.0000263459.11871.cd

4. Werner EF, Savitz DA, Janevic TM, et al. Mode of delivery and neonatal outcomes in preterm, small-for-gestational-age newborns. Obstet Gynecol 2012;120(3):560-4. doi: 10.1097/AOG.0b013e318265b16c

5. Hezelgrave N, Anderson-Knight $\mathrm{H}$, Webster L, et al. Commentary on 'A multicentre randomised controlled trial comparing elective and selective caesarean section for the delivery of the preterm breech infant'. BJOG 2014;121 Suppl 7:54-7. doi: 10.1111/1471-0528.13155

6. Penn ZJ, Steer PJ, Grant A. A multicentre randomised controlled trial comparing elective and selective caesarean section for the delivery of the preterm breech infant. BJOG 2014;121 Suppl 7:48-53. doi: 10.1111/1471-0528.13212

7. Sentilhes L, Brun S, Lorthe E, et al. Preterm Breech Presentation: A Comparison of Intended Vaginal and Intended Cesarean Delivery. Obstet Gynecol 2016;127(6):1170. doi: 10.1097/AOG.0000000000001458

8. Bergenhenegouwen LA, Meertens $L$, Schaaf J, et al. Vaginal delivery versus caesarean section in preterm breech delivery: a systematic review. Eur J Obstet Gynecol Reprod Biol 2014;172:1-6. doi: 10.1016/j.ejogrb.2013.10.017

9. Grabovac M, Karim JN, Isayama T, et al. What is the safest mode of birth for extremely preterm breech singleton infants who are actively resuscitated? A systematic review and metaanalyses. BJOG 2017 doi: 10.1111/1471-0528.14938

10. Bergenhenegouwen L, Vlemmix F, Ensing S, et al. Preterm Breech Presentation: A Comparison of Intended Vaginal and Intended Cesarean Delivery. Obstet Gynecol 2015;126(6):1223-30. doi: 10.1097/AOG.0000000000001131

11. Hills F, Way M, Sekar R. Mode of delivery for singleton extreme preterm breech fetuses: A 10 year retrospective review from a single tertiary obstetric centre. Aust N Z J Obstet Gynaecol 2017 doi: 10.1111/ajo.12681

12. Niles KM, Barrett JFR, Ladhani NNN. Comparison of cesarean versus vaginal delivery of extremely preterm gestations in breech presentation: retrospective cohort study. J Matern Fetal Neonatal Med 2017:1-6. doi: 10.1080/14767058.2017.1401997

13. Lorthe $E$, Sentilhes $L$, Quere $M$, et al. Planned delivery route of preterm breech singletons and neonatal and 2-year outcomes: a population-based cohort study. BJOG 2018 doi: 10.1111/1471-0528.15466

14. Kayem G, Baumann R, Goffinet F, et al. Early preterm breech delivery: is a policy of planned vaginal delivery associated with increased risk of neonatal death? Am J Obstet Gynecol 2008;198(3):289 e1-6. doi: 10.1016/j.ajog.2007.10.794

15. Kayem G, Combaud V, Lorthe E, et al. Mortality and morbidity in early preterm breech singletons: impact of a policy of planned vaginal delivery. Eur J Obstet Gynecol Reprod Biol 2015;192:615. doi: 10.1016/j.ejogrb.2015.06.019

16. Zeitlin J, Manktelow BN, Piedvache A, et al. Use of evidence based practices to improve survival without severe morbidity for very preterm infants: results from the EPICE population based cohort. BMJ 2016;354:i2976. doi: 10.1136/bmj.i2976 
17. Smith LK, Blondel B, Van Reempts P, et al. Variability in the management and outcomes of extremely preterm births across five European countries: a population-based cohort study. Arch Dis Child Fetal Neonatal Ed 2017 doi: 10.1136/archdischild-2016-312100

18. Papile LA, Burstein J, Burstein R, et al. Incidence and evolution of subependymal and intraventricular hemorrhage: a study of infants with birth weights less than 1,500 gm. J Pediatr 1978;92(4):529-34.

19. Draper ES, Manktelow BN, Cuttini M, et al. Variability in Very Preterm Stillbirth and In-Hospital Mortality Across Europe. Pediatrics 2017;139(4) doi: 10.1542/peds.2016-1990

20. Edstedt Bonamy AK, Zeitlin J, Piedvache A, et al. Wide variation in severe neonatal morbidity among very preterm infants in European regions. Arch Dis Child Fetal Neonatal Ed 2018 doi: 10.1136/archdischild-2017-313697

21. Zeitlin J, Bonamy AE, Piedvache A, et al. Variation in term birthweight across European countries affects the prevalence of small for gestational age among very preterm infants. Acta Paediatr 2017 doi: 10.1111/apa.13899

22. Rosenbaum $P$, Rubin $D$. The central role of the propensity score in observational studies for causal effects. Biometrika 1983;70(1):41-55.

23. Pearl J. The foundations of causal inference. Sociological Methodology 2010;40(1):75-149.

24. Kallen K, Serenius F, Westgren M, et al. Impact of obstetric factors on outcome of extremely preterm births in Sweden: prospective population-based observational study (EXPRESS). Acta obstetricia et gynecologica Scandinavica 2015;94(11):1203-14. doi: 10.1111/aogs.12726

25. Lodha A, Zhu Q, Lee SK, et al. Neonatal outcomes of preterm infants in breech presentation according to mode of birth in Canadian NICUs. Postgrad Med J 2011;87(1025):175-9. doi: 10.1136/pgmj.2010.107532 
Table 1: Characteristics of study sample and caesarean section rate for breech very preterm infants

\begin{tabular}{|c|c|c|c|c|c|}
\hline & $\begin{array}{l}\text { Number } \\
\text { of infants }\end{array}$ & $\begin{array}{c}\% \text { with } \\
\text { characteristic }\end{array}$ & $\begin{array}{c}\text { Number with } \\
\text { caesarean }\end{array}$ & $\begin{array}{c}\% \\
\text { caesarean }\end{array}$ & $\mathrm{p}$-value \\
\hline \multicolumn{6}{|l|}{ Maternal age } \\
\hline$<35$ years & 433 & 76.0 & 270 & 62.4 & 0.072 \\
\hline$\geq 35$ years & 137 & 24.0 & 97 & 70.8 & \\
\hline \multicolumn{6}{|l|}{ Parity } \\
\hline Nulliparous & 275 & 50.4 & 179 & 65.1 & 0.034 \\
\hline Multiparous, no previous caesarean & 198 & 36.3 & 116 & 58.6 & \\
\hline Multiparous, previous caesarean & 73 & 13.4 & 55 & 75.3 & \\
\hline \multicolumn{6}{|l|}{ PPROM (1) } \\
\hline No & 312 & 55.2 & 181 & 58.0 & 0.000 \\
\hline Yes & 253 & 44.8 & 183 & 72.3 & \\
\hline \multicolumn{6}{|l|}{ Infection (2) } \\
\hline No & 461 & 80.6 & 290 & 62.9 & 0.146 \\
\hline Yes & 111 & 19.4 & 78 & 70.3 & \\
\hline \multicolumn{6}{|l|}{ Antepartum haemorrhage $>20$ weeks } \\
\hline No & 439 & 78.1 & 296 & 67.4 & 0.008 \\
\hline Yes & 123 & 21.9 & 67 & 54.5 & \\
\hline \multicolumn{6}{|l|}{ Admission for preterm labour $>20$ weeks } \\
\hline No & 202 & 35.9 & 139 & 68.8 & 0.090 \\
\hline Yes & 360 & 64.1 & 222 & 61.7 & \\
\hline \multicolumn{6}{|l|}{ Any antenatal steroids } \\
\hline No & 77 & 13.7 & 36 & 46.8 & 0.000 \\
\hline Yes & 486 & 86.3 & 327 & 67.3 & \\
\hline \multicolumn{6}{|l|}{ Delivery in level III unit } \\
\hline No & 117 & 20.5 & 74 & 63.2 & 0.783 \\
\hline Yes & 455 & 79.5 & 294 & 64.6 & \\
\hline \multicolumn{6}{|l|}{ Delivery occurs same day } \\
\hline No & 477 & 86.4 & 323 & 67.7 & 0.046 \\
\hline Yes & 75 & 13.6 & 42 & 56.0 & \\
\hline \multicolumn{6}{|l|}{ Gestational age (3) } \\
\hline 24-25 weeks & 140 & 24.5 & 49 & 35.0 & 0.000 \\
\hline 26-27 weeks & 146 & 25.5 & 98 & 67.1 & \\
\hline 28-29 weeks & 120 & 21.0 & 92 & 76.7 & \\
\hline 30-31 weeks & 166 & 29.0 & 129 & 77.7 & \\
\hline \multicolumn{6}{|l|}{ Sex } \\
\hline Female & 235 & 41.1 & 154 & 65.5 & 0.618 \\
\hline Male & 337 & 58.9 & 214 & 63.5 & \\
\hline \multicolumn{6}{|l|}{ SGA } \\
\hline$<3$ rd percentile & 30 & 5.2 & 22 & 73.3 & 0.044 \\
\hline $3^{\text {rd }}$ to 10 th percentile & 44 & 7.7 & 35 & 79.5 & \\
\hline$>$ 10th percentile & 498 & 87.1 & 311 & 62.4 & \\
\hline \multicolumn{6}{|l|}{ Country (region) } \\
\hline Belgium (Flanders) & 45 & 7.9 & 36 & 80.0 & 0.000 \\
\hline Denmark (Eastern region) & 12 & 2.1 & 11 & 91.7 & \\
\hline
\end{tabular}




\begin{tabular}{|c|c|c|c|c|}
\hline Estonia (entire country) & 17 & 3.0 & 16 & 94.1 \\
\hline $\begin{array}{l}\text { France (Burgundy, lle-de-France } \\
\text { and the Northern region) }\end{array}$ & 101 & 17.7 & 49 & 48.5 \\
\hline Germany (Hesse and Saarland) & 38 & 6.6 & 35 & 92.1 \\
\hline $\begin{array}{l}\text { Italy (Emilia-Romagna, Lazio and } \\
\text { Marche) }\end{array}$ & 79 & 13.8 & 58 & 73.4 \\
\hline $\begin{array}{l}\text { The Netherlands (Central and } \\
\text { Eastern region) }\end{array}$ & 34 & 5.9 & 14 & 41.2 \\
\hline Poland (Wielkopolska) & 23 & 4.0 & 16 & 69.6 \\
\hline $\begin{array}{l}\text { Portugal (Lisbon and Tagus Valley, } \\
\text { and North region) }\end{array}$ & 70 & 12.2 & 59 & 84.3 \\
\hline $\begin{array}{l}\text { UK (East Midlands and Yorkshire \& } \\
\text { Humber regions) }\end{array}$ & 135 & 23.6 & 56 & 41.5 \\
\hline Sweden (greater Stockholm area) & 18 & 3.1 & 18 & 100.0 \\
\hline
\end{tabular}

NOTE: (1) Preterm Premature Rupture of Membranes (2) noted as an indication for delivery or chorioamnionitis (3) defined as the best obstetric assessment based on information on last menstrual period and antenatal ultrasounds, which are part of routine obstetrical care in all regions. 
Table 2: Policies to undertake systematic caesarean section for breech very preterm infants by gestational age

\begin{tabular}{|c|c|c|c|c|c|c|c|c|c|c|}
\hline & \multirow{2}{*}{$\begin{array}{c}\mathrm{N} \\
\text { Units } \\
+\end{array}$} & \multirow{2}{*}{$\begin{array}{c}\text { No } \\
\text { Resp- } \\
\text { Onse* } \\
\end{array}$} & \multicolumn{8}{|c|}{ Gestational age in weeks } \\
\hline & & & 24 & 25 & 26 & 27 & 28 & 29 & 30 & 31 \\
\hline Belgium (Flanders) & 9 & 1 & $2(25.0)$ & $6(75.0)$ & $8(100)$ & $8(100)$ & $8(100)$ & $8(100)$ & $8(100)$ & $8(100)$ \\
\hline Denmark (Eastern region) & 8 & 0 & $3(37.5)$ & $5(62.5)$ & $7(87.5)$ & $7(87.5)$ & $7(87.5)$ & $7(87.5)$ & $7(87.5)$ & $7(87.5)$ \\
\hline Estonia (entire country) & 2 & 0 & $0(0)$ & $1(50.0)$ & $1(50.0)$ & $1(50.0)$ & $2(100)$ & $2(100)$ & $2(100)$ & $2(100)$ \\
\hline $\begin{array}{l}\text { France (Burgundy, Ile-de-France, Northern } \\
\text { region) }\end{array}$ & 22 & 2 & $3(15.0)$ & $5(25.0)$ & $8(40.0)$ & $9(45.0)$ & $9(45.0)$ & $9(45.0)$ & $7(35.0)$ & $8(40.0)$ \\
\hline Germany (Hesse and Saarland) & 13 & 0 & $11(84.6)$ & $11(84.6)$ & $11(84.6)$ & $12(92.3)$ & $13(100)$ & $13(100)$ & $13(100)$ & $13(100)$ \\
\hline Italy (Emilia-Romagna, Lazio and Marche) & 21 & 0 & $12(57.1)$ & $15(71.4)$ & $16(76.2)$ & $17(81.0)$ & $18(85.7)$ & 19 (90.5) & $21(100)$ & $21(100)$ \\
\hline The Netherlands (Central and Eastern region) & 2 & 0 & $0(0)$ & $0(0)$ & $0(0)$ & $0(0)$ & $0(0)$ & $0(0)$ & $0(0)$ & $0(0)$ \\
\hline Poland (Wielkopolska) & 4 & 0 & $1(25)$ & $1(25)$ & $2(50)$ & $2(50)$ & $4(100)$ & $4(100)$ & $4(100)$ & $4(100)$ \\
\hline $\begin{array}{l}\text { Portugal (Lisbon and Tagus Valley, and North } \\
\text { region) }\end{array}$ & 17 & 0 & $6(35.3)$ & $10(58.8)$ & $14(82.4)$ & $15(88.2)$ & $16(94.1)$ & $16(94.1)$ & $16(94.1)$ & $16(94.1)$ \\
\hline $\begin{array}{l}\text { UK (East Midlands, Yorkshire, Humber } \\
\text { regions) }\end{array}$ & 20 & 1 & $0(0)$ & $0(0)$ & $0(0)$ & $1(5.3)$ & $3(15.8)$ & $3(15.8)$ & $3(15.8)$ & $3(15.8)$ \\
\hline Sweden (greater Stockholm area) & 5 & 0 & $1(20.0)$ & $4(80.0)$ & $5(100)$ & $5(100)$ & $5(100)$ & $5(100)$ & $5(100)$ & $5(100)$ \\
\hline All regions & 123 & 4 & 39 (32.8) & $58(48.7)$ & $72(60.5)$ & 77 (64.7) & 85 (71.4) & $86(72.3)$ & $86(72.3)$ & $87(73.1)$ \\
\hline
\end{tabular}

${ }^{+}$Number of unit responding to the maternity unit questionnaire. ${ }^{*}$ No Response - entire question skipped: missing response for all gestational ages 
Table 3 Outcomes of breech very preterm infants by mode of delivery and gestational age group

\begin{tabular}{|c|c|c|c|c|c|c|}
\hline \multirow[t]{2}{*}{ Outcomes } & \multirow{2}{*}{$\begin{array}{l}\text { Caesarean } \\
\text { delivery } \\
\text { n/N (\%) }\end{array}$} & \multirow{2}{*}{$\begin{array}{c}\text { Vaginal } \\
\text { delivery } \\
\text { (reference) } \\
\mathrm{n} / \mathrm{N}(\%)\end{array}$} & \multirow{2}{*}{$\begin{array}{c}\text { Model } 0 \\
\text { mixed effects model } \\
\text { no adjustment } \\
\text { Crude OR }[95 \% \mathrm{Cl}]\end{array}$} & \multirow{2}{*}{$\begin{array}{c}\text { Model } 1 \\
\text { Mixed effects model } \\
\text { adjusted } \\
\text { Adjusted OR }[95 \% \mathrm{Cl}]\end{array}$} & \multicolumn{2}{|c|}{$\begin{array}{c}\text { Model } 2 \\
\text { propensity score matching } \\
\text { adjustment on GA and country }\end{array}$} \\
\hline & & & & & $\mathrm{N}$ & Adjusted OR $[95 \% \mathrm{Cl}]$ \\
\hline \multicolumn{7}{|l|}{ All infants24-31 weeks } \\
\hline Mortality/IVH 3-4/cPVL & $65 / 366(17.8 \%)$ & $80 / 201(39.8 \%)$ & $0.33[0.22 ; 0.48]$ & $0.50[0.30 ; 0.81]$ & 214 & $0.72[0.41 ; 1.29]$ \\
\hline Mortality & $41 / 368(11.1 \%)$ & $61 / 204(29.9 \%)$ & $0.29[0.19 ; 0.46]$ & $0.51[0.29 ; 0.88]$ & 214 & $0.65[0.34 ; 1.24]$ \\
\hline Mortality $\leq 6$ hours & $6 / 368(1.6 \%)$ & $25 / 204(12.3 \%)$ & $0.12[0.05 ; 0.29]$ & $0.14[0.04 ; 0.48]$ & 214 & $0.27[0.05 ; 1.37]$ \\
\hline Apgar $<7$ at $5 \mathrm{~min}$ & $80 / 354(22.6 \%)$ & $77 / 186(41.4 \%)$ & $0.41[0.27 ; 0.61]$ & $0.46[0.27 ; 0.76]$ & 186 & $0.62[0.34 ; 1.15]$ \\
\hline IVH 3-4/cPVL & $39 / 359(10.9 \%)$ & $40 / 174(23.0 \%)$ & $0.41[0.25 ; 0.66]$ & $0.59[0.33 ; 1.07]$ & 202 & $0.72[0.35 ; 1.48]$ \\
\hline \multicolumn{7}{|l|}{ 26-31 weeks } \\
\hline Mortality/IVH 3-4/cPVL & 49/317 (15.5\%) & $29 / 113(25.7 \%)$ & $0.53[0.31 ; 0.9]$ & $0.54[0.29 ; 1.01]$ & 150 & $0.92[0.43 ; 1.98]$ \\
\hline Mortality & $27 / 319(8.5 \%)$ & $19 / 113(16.8 \%)$ & $0.46[0.24 ; 0.86]$ & $0.47[0.22 ; 1.00]$ & 150 & $0.88[0.34 ; 2.24]$ \\
\hline Mortality $\leq 6$ hours & $5 / 319(1.6 \%)$ & $10 / 113(8.8 \%)$ & $0.16[0.05 ; 0.49]$ & $0.12[0.03 ; 0.59]$ & 150 & $0.24[0.03 ; 2.25]$ \\
\hline Apgar $<7$ at $5 \mathrm{~min}$ & $65 / 309(21 \%)$ & $36 / 109$ (33.0\%) & $0.56[0.34 ; 0.92]$ & $0.60[0.33 ; 1.08]$ & 136 & $0.69[0.32 ; 1.47]$ \\
\hline IVH 3-4/cPVL & $31 / 310(10 \%)$ & $15 / 102(14.7 \%)$ & $0.66[0.33 ; 1.3]$ & $0.64[0.29 ; 1.42]$ & 142 & $0.87[0.32 ; 2.42]$ \\
\hline \multicolumn{7}{|l|}{ 24-25 weeks } \\
\hline Mortality/IVH 3-4/cPVL & $16 / 49(32.7 \%)$ & $51 / 88(58.0 \%)$ & $0.35[0.17 ; 0.73]$ & $0.24[0.08 ; 0.66]$ & 72 & $0.45[0.16 ; 1.24]$ \\
\hline Mortality & $14 / 49(28.6 \%)$ & $42 / 91$ (46.2\%) & $0.43[0.19 ; 0.97]$ & $0.39[0.14 ; 1.10]$ & 74 & $0.45[0.17 ; 1.18]$ \\
\hline Mortality $\leq 6$ hours & $1 / 49(2 \%)$ & 15/91 (16.5\%) & $0.10[0.01 ; 0.85]$ & $0.20[0.02 ; 1.76]$ & 74 & $0.31[0.03 ; 3.34]$ \\
\hline Apgar $<7$ at $5 \mathrm{~min}$ & $15 / 45(33.3 \%)$ & $41 / 77$ (53.2\%) & $0.35[0.13 ; 0.96]$ & $0.20[0.04 ; 0.98]$ & 60 & $0.38[0.14 ; 1.06]$ \\
\hline IVH 3-4/cPVL & $8 / 49$ (16.3\%) & 25/72 (34.7\%) & $0.37[0.15 ; 0.90]$ & $0.31[0.10 ; 0.97]$ & 68 & $0.48[0.15 ; 1.47]$ \\
\hline
\end{tabular}

Adjusted for: maternal age, parity, previous CS, antenatal steroids, pregnancy complications, gestational age, sex, SGA, and level of maternity unit, as coded in Table 1 
Table 4 Outcomes of breech very preterm infants by presence of a policy of systematic caesarean in their delivery unit

\begin{tabular}{|c|c|c|c|c|}
\hline \multirow{3}{*}{ Outcomes } & \multicolumn{2}{|c|}{ Policy of systematic caesarean } & \multirow{3}{*}{$\begin{array}{c}\begin{array}{c}\text { Unadjusted mixed } \\
\text { effects model }\end{array} \\
\text { Crude OR }[95 \% \mathrm{Cl}]\end{array}$} & \multirow{3}{*}{$\begin{array}{c}\begin{array}{c}\text { Adjusted mixed } \\
\text { effects model }\end{array} \\
\text { Adjusted OR }[95 \% \mathrm{Cl}]\end{array}$} \\
\hline & Yes & $\begin{array}{c}\text { No } \\
\text { (reference) }\end{array}$ & & \\
\hline & $\mathrm{n} / \mathrm{N}(\%)$ & $\mathrm{n} / \mathrm{N}(\%)$ & & \\
\hline \multicolumn{5}{|l|}{ All infants $\geq 24-31$ weeks } \\
\hline Mortality/IVH 3-4/cPVL & $54 / 283(19.1 \%)$ & $58 / 183(31.7 \%)$ & $0.51[0.33 ; 0.78]$ & $0.76[0.44 ; 1.28]$ \\
\hline Mortality & $35 / 284(12.3 \%)$ & $42 / 186(22.6 \%)$ & $0.48[0.29 ; 0.79]$ & $0.71[0.38 ; 1.31]$ \\
\hline Mortality $\leq 6$ hours & $6 / 284(2.1 \%)$ & $16 / 186(8.6 \%)$ & $0.23[0.09 ; 0.60]$ & $0.44[0.13 ; 1.45]$ \\
\hline Apgar $<7$ at $5 \mathrm{~min}$ & $62 / 274(22.6 \%)$ & $60 / 173(34.7 \%)$ & $0.48[0.27 ; 0.87]$ & $0.69[0.37 ; 1.27]$ \\
\hline IVH 3-4/cPVL & $32 / 277(11.6 \%)$ & $30 / 164(18.3 \%)$ & $0.58[0.34 ; 1.00]$ & $0.86[0.46 ; 1.61]$ \\
\hline \multicolumn{5}{|l|}{ 26-31 weeks } \\
\hline Mortality/IVH 3-4/cPVL & $35 / 236(14.8 \%)$ & $26 / 126(20.6 \%)$ & $0.67[0.38 ; 1.17]$ & $0.73[0.37 ; 1.45]$ \\
\hline Mortality & $18 / 237(7.6 \%)$ & $15 / 126(11.9 \%)$ & $0.61[0.30 ; 1.25]$ & $0.59[0.24 ; 1.46]$ \\
\hline Mortality $\leq 6$ hours & $3 / 237(1.3 \%)$ & $7 / 126(5.6 \%)$ & $0.22[0.06 ; 0.86]$ & $0.17[0.02 ; 1.26]$ \\
\hline Apgar $<7$ at $5 \mathrm{~min}$ & $44 / 234(18.8 \%)$ & $35 / 120(29.2 \%)$ & $0.57[0.32 ; 1.01]$ & $0.57[0.31 ; 1.06]$ \\
\hline IVH 3-4/cPVL & $23 / 231(10 \%)$ & $14 / 118(11.9 \%)$ & $0.80[0.37 ; 1.71]$ & $0.99[0.42 ; 2.34]$ \\
\hline \multicolumn{5}{|l|}{ 24-25 weeks } \\
\hline Mortality/IVH/cPVL & $19 / 47(40.4 \%)$ & $32 / 57(56.1 \%)$ & $0.53[0.24 ; 1.16]$ & $0.41[0.13 ; 1.27]$ \\
\hline Mortality & $17 / 47(36.2 \%)$ & $27 / 60(45 \%)$ & $0.69[0.32 ; 1.52]$ & $0.67[0.25 ; 1.81]$ \\
\hline Mortality $\leq 6$ hours & $3 / 47(6.4 \%)$ & $9 / 60(15 \%)$ & $0.40[0.09 ; 1.79]$ & $0.62[0.11 ; 3.53]$ \\
\hline Apgar $<7$ at $5 \mathrm{~min}$ & $18 / 40(45 \%)$ & $25 / 53(47.2 \%)$ & $0.92[0.40 ; 2.09]$ & $1.27[0.43 ; 3.73]$ \\
\hline IVH 3-4/cPVL & $9 / 46(19.6 \%)$ & $16 / 46(34.8 \%)$ & $0.46[0.18 ; 1.18]$ & $0.35[0.08 ; 1.49]$ \\
\hline
\end{tabular}

\section{Legend Figures}

\section{Figure 1: Flow chart for inclusions in study}

